\title{
Announcement: New Prices and Payment Policy for Color Figures in the Print Journal
}

Effective with manuscripts accepted for publication on or after July 1, 2007, APS will charge for publishing color figures in the print journal according to a simplified, flat-fee pricing scheme. The price for publishing a single color illustration will be US $\$ 800.00$. Each subsequent color figure in that article will cost US\$425.00.

This new fee structure will allow APS to streamline our operations by requiring advance payment for color charges. When an article is accepted for publication, the authors will receive confirmation of the amount due for color reproduction in the print journal. A formal invoice will follow this message within a few days of acceptance, together with payment instructions. The manuscript will not be forwarded to our composition vendor for publication until the invoice is paid, or a decision is made to publish the article without color in print. To avoid excessive delays in publication, if a response is not received within two weeks, the article will be sent to production with the figures designated as color online only. Publication charges and reprint charges will be invoiced separately, after publication of the article.

Of course, APS continues to make available the option of publishing color figures in the online journal only without cost to the authors (provided the figures are submitted according to APS guidelines). Please refer to http://authors.aps.org/tips.html for more information about color online only.

Published 22 June 2007

DOI: 10.1103/PhysRevD.75.110001

PACS numbers: 01.10.Cr 